\title{
Efficient Communication in Business Strategies
}

\author{
Adina Claudia Neamtu, Liviu Neamtu \\ Departament of Management, Marketing and Business Administrations, Constantin Brancusi University, Targu-Jiu, Romania
}

Email address:

neamtual@yahoo.com (A. C. Neamtu),professor.neamtu@yahoo.com (L. Neamtu)

\section{To cite this article:}

Adina Claudia Neamtu, Liviu Neamtu. Efficient Communication in Business Strategies. Science Journal of Business and Management. Vol. 3, No. 1, 2015, pp. 24-32. doi: 10.11648/j.sjbm.20150301.14

\begin{abstract}
The organization itself can be seen as being largely a construction of communication. Communication practice is eloquence, the way to compose and expose a message, to speak in a certain order. The communication's quality to ensure the accomplishment of objectives proposed by the communicator, is named efficiency. Communication efficiency is based on the capacity of a person to know how he has to act and what he has to do in order to accomplish what he proposed, with minimum consumption of resources. The communication strategy of a corporation has to be coherent, to be a unit between internal and external communication. The close connection between communication strategy and the image of the corporation, in case they are opting for a new image, involves changes in the communication strategy. In this situation, internal communication aims that the new rules of the identity and the corporation image program to be understood, accepted and applied by all the employees and representatives of the company and that the external communication have as objective transmission of a new message to the public, a new identity, a new orientation of the organization, of its present coordinated. The image of a corporation may vary from one public segment to another; but the identity has to be consistent. The identity confers specificity, contributing by its elements to immediate recognition of an organization, at the first level of visual contact. All these are transmitted by a complex communication process, split into a logic succession, such: typification, interpretation, selection, organization, operationalization.
\end{abstract}

Keywords: Communication process, Business Communication, Communication Strategy

\section{Introduction}

Business communication represents the process of transmitting a message to the receiver, directly or indirectly linked to the accomplishment of some professional tasks [9], accomplished by people with some formal organizations.

The specific of business communication is given by the particular context in which this takes place [26]. The main coordinates of the business communication context are:

- experience of a formal organization, its capacity of forming and maintaining an organizational culture; the formal organization is created and composed of people, the efforts of which have to be coordinated, an essential role in this sense being that of communication [5].

- connection of company communication on the whole with work tasks of each employee; the work tasks of employees can be accomplished only by interaction with other members of the organization or with staff, groups or organization from outside. Each depends on each, each needs, except for other resources, information, support, advices, ideas.
The manager transmits an order to his subaltern or explains to him how to execute an action, the members of a team design a new strategy and exchange ideas, the seller and the buyer establish the terms and condition of a transaction [18]. Correct or incorrect communication will affect the way tasks are realised in time, with minimum consumption of resources, etc.

- roles of people as employees with work tasks, in the context of their involvement in the ample communication process performed on company level and relations with business partners.

The social role of work is given by the entirety of typical or atypical behaviours which are expected by those around, from the employees.

Each person seems to play a role: at home, in the social life or at the workplace (the role of manager, father, and, protector, etc.). The role in work is defined by its behaviour and by the set of relations it establishes [6]. 


\section{Methodology}

A new image of an organization supposes good collaboration between marketing, design and communication abilities [30]. In absence of these convergences, the image is inconsistent and does not transmit to the people the desired message.

The components of the communication strategy of a company are [31]: image and identity of the corporation; publicity by the company and means of spreading publicity; relations with mass media; marketing communications; financial communications; communication with the employees; relations with the community; charitable actions of the corporation; relations with the authorities; communication in crisis situations; continuity; profitability; social politics.

The entire communication strategy gravitates around the image and the identity of the corporation. The internal and external communication strategy is the liaison between the company's goals and the objectives of its image and identity [32].

Communication is a fundamental feature of existence. All management functions are accomplished by communication, as a process of understanding between people with the aid of information transfer.

A clear and consistent image that needs no adjustment for over several years, depending on the modifications in art, design, marketing and advertising trends, maintaining a powerful position in the market. A good image is built up based on three essential elements: design, organization, behaviour.

Identity of a corporation combines two conflicting dimensions [33]: the need of permanent adjustment to the changes in the throwaway society, to the preferences and needs of people; a certain durability, cohesion and generation of familiar links to the public, to the consumers on diverse segments of the market.

The image of a corporation includes [34] everything, from the visual impression created by the logo, header, uniform, leaflets, company board or advertisement, from the odour in shops, attractive posters, air conditioning, from the environment created by the internal and external design of the building, to the customers pleasant or unpleasant experience caused by the quality of the products and services. The image of a corporation includes tangible aspects (visual elements), as well as its non-tangible aspects (social responsibility, ethics, concern for environment, charity actions, etc.), all related to the classical sense: products and services - have in regard the quality of products and care for the consumer; social responsibility, relations with the community, this behaviour and business with the community; environment - offices, factories, exhibition halls, etc.; communications - advertising, public relations, communication with the staff, leaflets, corporation identity programs.

Communication is a fundamental feature of existence [28]. The safest way to a more beautiful life, to personal and professional happiness remains communication [2]; it helps you to tell people near you what you feel, what you want and what you don't want, avoiding accumulation of frustration due to convenience, fear or inability to freely [24] but with common sense and elegantly, express what you think.

Despite we refer to business communication, we also have to start from deeply human bonds of communication; it belongs par excellence to humans, intelligent beings, which can defeat their own inhibitions, expression deficiencies, accumulated fixations, native deficiencies of interacting with the others [12].

This can be done by education [21], tolerance towards the others [8] own accommodation efforts, language, gestures and mimic [3]. Sometimes it is more difficult to convince yourself than the others, but in case you have succeeded this you can say that you have made the first step towards communication.

As a methodology, the assessment of evolution from one stage to another in the process of communication was done by direct observation, the study of human behaviour, psychological tests and other qualitative methods as: free individual discussions, non-directive, semi-directive, or associative techniques for stimulating creativity [14].

This led to the inclusion of every person, who is part of a group and adheres to its organizational cultural values, in a particular evolutionary stage.

\section{Image and Identity}

All management functions are accomplished by communication, as a process of understanding between people with the aid of information transfer.

Identity of a corporation combines two conflicting dimensions:

- the need of permanent adjustment to the changes in the throwaway society, to the preferences and needs of people, ,

- a certain durability, cohesion and generation of familiar links to the public, to the consumers on diverse segments of the market.

The image of a corporation include everything, from the visual impression created by the logo, header, uniform, leaflets, company board or advertisement, from the odour in shops, attractive posters, air conditioning, from the environment created by the internal and external design of the building, to the customers pleasant or unpleasant experience caused by the quality of the products and services [25].

The image of a corporation includes tangible aspects (visual elements), as well as its non-tangible aspects (social responsibility, ethics, concern for environment, charity actions, etc.), all related to the classical sense: products and services have in regard the quality of products and care for the consumer; social responsibility, relations with the community, this behaviour and business with the community; environment - offices, factories, exhibition halls, etc.; communications advertising, public relations, communication with the staff, leaflets, corporation identity programs.

Diversity and complexity of products and services, multiplication of the number of companies led to transformation of the image and identity into a means of differencing, which allows the buyer to choose from the great 
number of offers [16]. People got to buy the image, not the product as such.

A clear and consistent image which needs no adjustment for over several years, depending on the modifications in art, design, the marketing and advertising trends, maintaining a powerful position in the market. A good image is built up based on three essential elements: design, organization, behaviour.

It is considered that the image of a corporation is the same with the image of the company that the public sees, instead the identity of a company is the image the company endeavours to obtain in order to built up god reputation before its clients.

The image form into reflecting the reality of the organization, reality which differ from one part to the other; it is perceived by the large public as brand image, being mistaken in practice for several times with the sense and notoriety a brand have among them.

The identity is the visual manifest of the image, which is transmitted by the logo, products, services, buildings, uniforms and all tangible communication modalities of the corporation [1].

It is more than an image, but it can not be understood except in the context of the image the organization have and is reflected, essentially, by its brand.

The image of the brand ensures identity and the later ensures notoriety and prestige to the brand as such. A good image determines the identity of organization and both of them are assimilated by the public by the attention grant to the brand it represents.

Among the advantages of a good image of the corporation are: increased sales; supporting development of a product; strengthened financial relations; harmonizes the relations with the employees; increased possibility of recruitment; crisis management [19].

In general, the image of a company ( more or less faithful reflection of identity), even if it is perceived by the majority of those who get into contact with it, in a way that it is differenced from others by certain features, it gets to them in a rather dispersed form.

The image of the other offers the possibility of understanding the mode in which are established the relations between the two groups close in time and space, and the mode the dialogue between them takes place explains the mechanism on which are based their relations. The image of the other is important for our own image because alteration catalyzes the process of forming the own identity.

Only by comparison with the other, at a different element, a group, a community crystallizes its own image, outlining what is own and different: language hedges, language difficulties, confused expressions and words or different meanings; environment hedges: improper informational support, differences between the emitter's and the receiver's education, improper work climate; hedges due to the emitter's or receiver's position: the image of the other sometimes accompanied by preconceived ideas, the communicator's feelings, wrong perception of the subject under discussion; hedges of conception: suppositions, lack of attention and interest at receiving, wrong expression of the message, hasted conclusions; physical hedges: distance, space; social hedges: different concept of life; gnoseological hedges: missing experience, knowledge; sociological-psychological hedges: customs, traditions, prejudices; geographic hedges: borders in space; historic hedges: distance over time; state-political hedges: different political regimes; economic hedges: lack of financial means; technical hedges: lack of technique or out-of-date technologies; linguistic hedges: lack of foreign languages knowledge or defective knowledge; psychological hedges: perception, memory, beliefs; response hedges: the message does not meet the needs of the individual or is wrong understood by him.

Solutions for removing these hedges are: communication planning, establishing resources and communication methods, establishing their purpose, selection of the proper moment for performing it, establishing the message transmission support [23], clarification of the ideas before implementation, use of a proper language, existence of a possible permanent control, but especially preventive by information transmission channels.

Through communication can be transmitted, by words, symbols, gestures and signs, distinctive elements as: ideas, as comprising, fundamental principles of logic knowledge; thoughts, as result of thinking, musing, imagination, fantasy and inspiration desires and intentions of the complex thinking process; feelings, as attitudes, affection and emotional beliefs of people related to reality; opinions, as opinions and musing, personal judgement about different stimulations or environmental reality [4].

\section{Organizational Communication in the Group}

All these are transmitted by a complex communication process, split into a logic succession, such: identification of the public, the audience to which is destined the message, its structure; establishing the main objectives of communication; elaboration of the content and form of message; identification and selection of the means of communication; permanent organization, coordination and control of communication, from the emitter to the receiver.

Within the groups can be developed certain team-work, characterized by: hierarchy, dynamics, structure, mentality [10].

Hierarchy in any group is established a certain hierarchy of the group; those with more authority within the group become leaders, while the anonymous let themselves influenced by opinion shapers. The social grade, the hierarchy establish the action to contact the others, or not and if the grade does not work, there is no self-respect and so are often enough generated distancing. By violent or non-violent conflicts inside the group is checked in fact cohesion of its members and the stable dynamic balance. It is permanently required a rebalancing.

Dynamics of the group is the mode of communication inside the group and reflects even the hierarchy of the respective group. In each group there is a communication hierarchy which is identical to the social hierarchy of the group. Depending on the social organization of the group there 
are specific ways by which individuals get to each other from communication standpoint. Solidarity occurs within the group and consists of the feeling of community, in identification of individuals pertaining to the group with other members, as well as identification of personal interest of each group member with the interest of all members. It manifests by similar actions and feelings, by transmitting the same attitudes and appreciation criteria to all group members, by all members using identical action methods in a certain issue [22].

Group structure in social life occur very different images of the groups, therefore the issue of ranking is important for clear analysis, as detailed as possible of the mode of group establishing, considering different ranking criteria: based on ethnic or racial status, based on cultural development levels, based on tasks or functions accomplished by groups within larger collectivities, based on prevailing relations between members, based on different types of links occurring within groups, rankings based on other principles.

Mentality of a group is a clear proof of cohesion, balance. On general level, mentality is defined as an entirety of opinions, prejudices, beliefs which determine and influence the way of thinking by individuals, human groups, peoples. It marks also a particular way of feeling, thinking, reacting, specific to a group of persons or a people, respectively a community.

Besides, collective mentalities characterize a group, a collectivity composed of those who adopt a common attitude on a established object (e.g. mentality of a sect, a school, a congregation, of an age group).

Small groups have a simple structure, i.e. they are exclusively composed of members and have no sub-groups, but they can be part of larger collectivities, of other types. Therefore, a large group could be the people, state, an independent confessional group, because it is no more part of larger groups. Within the groups which occur in each society, an important role play family, social classes, groups with purpose (sports, political parties), territorial groups (village, city).

Communication as the act itself, is a system of message transmittal, which are taken over by people (receivers) from people around them (emitters) and arranged in order to be understood, conceptualized as a process [29], as shown in figure no. 1:

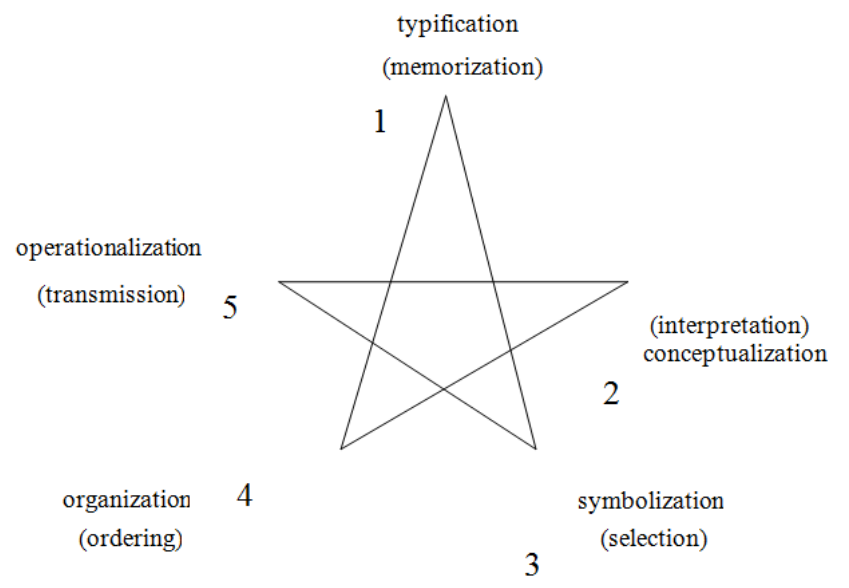

Figure no. 1. Content of the communication
Communication has a series of essential functions with a fundamental role on the group: adjusts behaviour of individuals, allows presence of influencing and dominating phenomena (every group is stratified, there is no egalitarian group), it generates movement, interest, locomotion to the objective of the group, facilitates performance of some tasks derived from the objectives, ensures cohesion of the group, it put forward the group (each group tries to affirm its individuality), it has a therapeutical role by protecting the group from foreigners, it is a factor of social-cultural unit, makes the group became reference for the individual because most of the members need a representative and cannot live without bench-marks and by communication we find what this common norm is - what is right, what is wrong, what is or not popular.

Social reality is structured on three levels: that of social personality (personality resulted from socialization), that of action and social relations (complexity of interrelations established inside concrete forms of social organization), that of the global social system.

\section{Features of Business Communication}

Business communication has the following main features:

- prevalent pragmatic feature: is determined by aiming some practical purposes. In the professional activity dominates the practical function of language. The individual seeks to produce a change in behaviour or an attitude of his colleagues. Some of the reasons why a manager communicates are: to transmit orders, to control their accomplishment, to transmit information, to collect information, to appraise performance, to hire the best candidate for a job, to motive, to instruct, so support a subaltern in execution of his tasks, to obtain information about the investment plan, to convince the buyer to buy products, etc.

- concern for efficiency: efficiency suppose that the communication process take place with consumption of resources as low as possible. Professional communication aims leading and resolving immediate problems, occurred during performance of activities with consumption of resources as low as possible. Time is a rare resource and therefore communication tend to be concise, precise, directly addressing the subject under discussion, except for everyday communication, where we like to comment everything, to gossip or communication in art, where the communicator affirms a personal style.

- adjustment of the message depending on the public: in business communication is considered that the task of the communicator to make a message easy to understand. The purpose of the communicator is to realize messages adjusted to the interlocutor, in order to be easy understood and convincing.

- creation of a favourable image: the image of an organization is built on harmony between performance and communication. In a normal economy, low 
performance can not be made up for a long time, no matter how intense publicity an image creation; the reverse remain valid: good performance bring not always a favourable perception.

The today's business man recognizes how important it is to the interlocutor a good impression about himself, about his products and his organization.

The predominant pragmatic feature of business communication put under discussion some criteria for appreciating success in communication. The main criterion is the amount in which the communicator accomplishes the proposed purpose. When he met the objective, communication was successful, in the contrary, it was a failure.

This process can have a formal character, given by the actions especially organized by economic structures, general organizations, as well defined and coordinated campaigns or promotional programs and informal character, given by the intrinsical content of the information transmitted by the marketing mix elements, other elements characteristic to each category of products or services.

Building up and development of its image, establishment of good relation with the main partners, success of the contact to the clients depend on the way the organization communicates. Approaching communication issues involve discussing also other important aspects, such as: intentionality, the intention by the emitter to transmit a message; existence of a reality to which refers the message; existence of a message or a code with the aid of which is build up the message; the activity performed by both participants, the emitter and the receiver; the effect of the communication process; message transmission technology; the existence of public interest in the transmitted message, i.e. existence of an interest in the message issued; the context of communication.

Communication got a wide spread; toady everything or almost everything is communication: advertising, public relation, marketing become from concepts dynamics and complex communication systems.

We talk about a group when inter-personal relations are frequent, consistent and durable. There are certain factors which have to be ensured in order to realize contacts: spatial element or space in life where individual get into contact; social, i.e. relational, element (relation between teacher and student or physician -patient); normative element of human relations (refers to a set of social statutes which each person has).

Communication can be the best or the worst thing, because finally, as it is efficient (it meets its goal), it can generate development of the business spirit in favour of truth and complete success and this is a form of morality which involves transformation into faultless actors, capable to lead the target public how and where they want, finally conquering it. The communication theory is based on rhetoric [17], while communication practice per se is eloquence, the way to compose and expose a message, to speak in a certain order, called the art of disposition, which establish in fact the dedicated parts of the speech: exordim: the opening remark which mainly aims catching attention, awake interest, realized links between the speaker and the public; proposal: includes the proposed topic, the object of discussion, briefing of the topic of discussion; division: is the structure of the speech which refers clearly to parts, chapters, sections, paragraphs and the order these are exposed; narration: is the longest part of a speech, it creates a world in the mind of the public, exposes facts, episodes, actions which took place, by respecting a certain order in relating them and creating connections between different characters: confirmation: refers entirely to proofs, testimonies, demonstrations by which are confirmed the presented facts of the speech or which support the exposed opinions, having a logic link to these; rejection of the adverse thesis: is based on the advantage which can reject possible objections or contrary arguments; digression: is like a short break, with the intention to recreate the public, to relax the atmosphere or to avoid a clinching aspect of the exposure; conclusion; is the end of exposure with the role to point the main conclusions and to create a certain link, beneficial for the future, with the public.

\section{Business Communication Strategy}

The communication's quality to ensure the accomplishment of objectives proposed by the communicator, is named efficiency. Communication efficiency is based on the capacity of a person to know how he has to act and what he has to do in order to accomplish what he proposed, with minimum consumption of resources.

The communication strategy of a corporation has to be coherent, to be a unit between internal and external communication. Also, it has always to be kept in mind the necessity of an indissoluble bond to the strategy of the entire corporation. Only in these conditions can be talked about efficient communication, capable to create the wanted image. Communication strategy supports implementation the organization strategy by harmonizing and ensuring successful adjustment of the organization to its operation environment.

Such strategy distinguishes itself by a long term concern for social politics and ethics, the production plan and conditions being linked to the social status of the employees [20]. The image of a company is nothing else but an extension in the plan of notoriety which they enjoy, its politics.

The close connection between communication strategy and the image of the corporation, in case they are opting for a new image, involves changes in the communication strategy. In this situation, internal communication aims that the new rules of the identity and the corporation image program to be understood, accepted and applied by all the employees and representatives of the company and that the external communication have as objective transmission of a new message to the public, a new identity, a new orientation of the organization, of its present coordinated.

Change in corporation supposes convergence between identity (visual element of the organization), organizational behaviour and communication strategy. If pot identifies identifies three steps in creating a new image of an organization : change of identity (visual elements), change in organizational behaviour, change in communication strategy. 
The entire communication strategy gravitates around the image and identity oof the corporation. The internal and external communication strategy is being the bond between the objectives of the company and the objectives of its image and identity.

It is hard for the consumer, who is daily assaulted by thousands of products, to remember the history of the company, its involvements, the transmitted message and so on.

Therefore the brand is probably the most used and efficient communication instrument of identity. Every day we are assaulted by brands, but behind each we can find a whole story, a certain format and certain psychological - social involvements. There are brands we recognise immediately and the story of which we know, brands known in the entire world.

For today consumer it is not enough that a product have quality, at a reasonable price and is nicely wrapped, he needs also the guarantee that, by consuming it, he has a certain notoriety, which characterizes him and brings him close to the community of people who share the same principle or lifestyle, symbolized by consuming the same type of product.

Therefore, the brand is the central point of the relation Producer/Consumer and represents a contract, in that the first makes an offer the consumer, willing to accept, has to take it.

Among physical and tangible aspects of this promise, there is the image of the proposed brand, the promised possible world, the territory which is the evolution scene of the brand.

Some aspects of this promise are identified: the consumer has to agree with this promise, and, several brand being in competition, it is logic that each brand address a target public. i.e. to have a certain category of consumers to which it address.

Life cycles of a brand: apart from the life cycle of a product, so easy and clear designed by marketing manuals, the life cycles of a brand are of a totally different nature. The life of a brand note steps in the general trace over time of the great brands. Depending on its desire to draw attention, to maintain or to assume the role of lead, the brands get to a new step of their lives: heroic, wisdom and mythical.

The heroic age is a new brand, which try to o impose itself among other brands and find a correspondent in the system of values of the society. Accordingly it define its targets: the physical area (i.e. the market segment) but especially the imaginary: it will be a brand of great social values, it will be a brand of cheerfulness, etc.; it is normal that the new brands assume values which are fashionable at the actual time, to be in areas of large actuality.

The age of wisdom in this step, the brand is already established. It can be a lot calmer in communication, certain reasonableness, appropriate to the age. The greatest danger of this step is a certain routine which lead to a certain stagnation and freezing of the brand in certain coordination, which may be are still valid, but have to be updated (in other words, sometimes must only be changed their communication strategy, not the values). Most times, the great brands try in this step to enrich the offered possible world. Many brands simply extend geographically, other organizations develop new brands under the umbrella of the same company or add new values, trying to diversify their target [15].

Mythical age is the case of great brands, known in some cases for over 100 years. They already seem eternal. Very many grown up or old people know the famous logo since their childhood. Some of them become real archetypes, maintaining over time the same main values.

This involvement, first of all the fact that a product is of high quality and of known quality; the brand is always associated with certain symbols, certain real and ideal features. The brand is in fact a symbol, a directed way of making known the identity of a company, it is the argument of the image of the organization.

Ultimately, the basic features of a brand are credibility and legitimacy. The brand is a synthesis of all elements: physical (the product by itself, the wrapper), aesthetics, rational and emotional.

The owner of a brand therefore must permanently make sure that the values and qualities of the brand are maintained and to orient toward attracting consumers and adjust to a permanently changing society.

The brand is more than a complex symbol. It can have the following significance: the features of a product; the advantages offered by the product; the values; concepts; personality; users.

Creation of that tangible and intangible set of elements of a brand (be it a producer or an organization) has to be realized according to a certain general strategy. Given the selective attention by those to whom is addressed the brand, each element, physical and immaterial, is important.

Shortly, in construction and communication of a brand everything count: the name, the logotype, design, notoriety, the contract, the life cycle of the brand, etc.

The name: the first expression of identity (of a person, a thing, etc.) is the given name by which you can recognize it immediately. The name of a brand can not be chosen randomly.

This is already the area of semiology, the significant role of language and word. The name must firstly vibrant with the type of product.

The associations the name can invoke in the consumer's mind must be carefully tracked and require a very interesting semantic and linguistic study. Therewith, it has to be easily remembered. The consumer must remember it even if he has heard or read it only once.

Usually [7], it has to be quickly associated with a suggestive word or idea, it has to be trans-linguistic, it must have a certain visual symmetry and a certain beat. The brand name must be, as possible, euphoric, declinable, easy identifiable, spellable, exportable, evocative and easy to memorize.

There is also a theft of a name, in its quasi-legal form. The market is full of products easily confusable with those of large companies.

These are in general solutions which indicate a certain quality and a certain standpoint related to ethics of the respective company. It has to be added that due to the low prices practiced, these brands address a certain category of consumers. 


\section{Result and Discussion}

Drafting the communication message can be considered as representing a special area, being an exclusive creation process, which depends essentially on imagination, intuition and aesthetics.

Business communication performs within or among formal organizations: enterprise, public institutions, non-profit institution.

The rules, procedures, values which the organization promote have an impact on the effective mode their members communicate. The organization itself can be seen as being largely a construction of communication. The members of organization live diverse experiences: installation of a new production equipment, changing the executive manager, decline of the market, change of the owner. With this occasion, by communication, they get to a common significance upon the events and they build their own body of common acquaintance.

In a totally different mode we have so called brands, which are rarely enough, in which the product name is its content itself, of its category [13].

Logotype is the first visual sign of a brand, its most obvious symbol. Usually it contain the name of a brand or its popular symbol, it has a certain design and specific colours. It is thought as a basic bench mark in perceiving the identity of a branch, which to be essentially remembered, like the physiognomy of a person: the Logo or the manufacturing brand are relatively small, but it represent a very important component of identity.

The logotype must be: powerful symbolic, striking, almost a cliché, somehow alike the heraldic signs. The logotype can be of a band-company or of a brand-product. By returning to our relation scheme image- identity - brand, we could say that the logo is the essential representation of the brand.

It is enough that a person sees the company logo in order to remind everything this brand means, the images associated with the name, the taste, colour, advertising he liked more, competitions and events sponsored by the brand, etc., in one word, a simple logo is enough for the person who see it to remember all associations, which are in fact elements of the identity and image of the company; he make a mental trip inside a large company.

It must be mentioned the fact that for many times the logotype is mistaken as brand. The logotype instead is the physical part of a brand, it is, as we said, the most obvious sign. The different logotypes, colours, writings try to reflect as well as possible the promoted features and images of the product.

Design is extremely important for creating the so-called atmosphere of the brand: the design have to express as well as possible the function of the object, by an entirety of techniques which allow for adjusting the form and colour of an image the brand formed around it: the beneficial must be beautiful.

Notoriety or consumership of the brand. This essential quality of a brand in strictly connected to elapsing a period of time, which has a powerful psychological-social aspect and is linked to marketing studies.

Communication of the brand is essential because this degree of notoriety indicates the position from which the brand is recognized the brand can further communicate. In other terms, notoriety represent the degree a band is known and recognized. Notoriety is tightly linked to psychical processes as perception or memory; it can be spontaneous and assisted.

Spontaneous notoriety is in fact the target of each brand creator. For this type of notoriety there is also the most envied situation when the name of a brand gets extremely popular, is replaced by the name of category as such.

Assisted notoriety is given by the brands the consumer choose from a list of several brands, as being the most familiar In other words, the consumer recognize them, but passively. He remind them and single them out from a row of several brands, for example on the shelf of a supermarket.

The contract (the world of a brand): any brand (as any commercial offer) promise a certain thing to the consumer, a contract which it tray to keep and enrich over time by new clauses. This contract, this promise situates between commercial and imaginary. In fact this is the challenge of the brand.

The communication system paradigm, as summation of five processes, can be explained by [11]: typology - perception, remember and giving the information (the individual in a emitter or receiver position localizes the information which he classifies and store it for later use); conceptualization reconsidering the messages through the prism of their transformation into principles and regularities in correlation with the nature of knowledge, obtaining and interpretation of information (once memorized, the data are interpreted and receive new meanings); symbolizations - everything that can be transmitted, can also be coded by symbols and their careful selection (new meanings represent also new way of expressing the content); organization - the mode of ranking and establishing framework of relationships inside which takes place in fact communication (new symbols are adjusted to the social context depending on relationship framework selection and functioning in a given context); operationalization - the way of transmitting a message (after completion follows transmission of the message in a physical form).

The communication channels reflect these processes and divide into two large categories: verbal and non-verbal, on one hand and formal and informal, on the other hand [27]. The communication channel has also an important role in transmitting the message from the emitter to the receiver. The aggregate channels form the communication environment on which depend quality and accuracy of message reception. The channels can occur as different forms: sound, image, odour, taste; receivers can prefer some in detriment of the others. Some individuals prefer images (television, films), others reading (books, newspapers, magazines) and others the sound (radio), etc.

\section{Conclusion}

Communication can be the best or the worst thing, because finally, as it is efficient (it meets its goal), it can generate development of the business spirit in favour of truth and complete success and this is a form of morality which involves 
transformation into faultless actors, capable to lead the target public how and where they want, finally conquering it.

Relation between identity, image, brand and complex elements which interweave in order to form and communicate them is very delicate.

There can not be made clear delimitations on the path of the organization from its internal organization to the elements which condense its existence in the mind of the consumer.

We could schematize these links in the communication process as an iceberg: what is seen at the outside, thus the result of communication, is only the top of a complex and homogenous structure, which starts from the inside of the organization.

The brand can be defined as an association between the name, slogan, sign, symbol or pictograph with the purpose of identifying goods or services rendered by a vendor / group of vendors and to difference them from those of the competitors; not only the image/slogan (briefly, the logotype) by itself means the brand, but also the mental associations which this induce in the consumer's mind; it can represent a synthesis of elements: tangible, the price, quality and degree of innovation, so called objective qualities and intangible, sensuousness, narrative abilities, the story of the product and involvement of the brand in the social-environmental reality, subjective, narrative an associative qualities of the brand.

Communication in business in performed, therefore, within a well-structured and defined organisational frame, which supposes operation.

Today people pregnant affirm their right to know and understand; in fact they are persona of an organization, of a company; in this context they have no choice: they have to affirm themselves, to talk, to dialogue, in fact to communicate. The better the capacity of an individual to communicate, the more powerful is his image and the image of the organization, the enterprise, the company, the institution he works for.

If communication serves building the own personal image of the company, communicating well, efficient, means to attach a positive, favourable, sometimes rich and coherent image.

A new image of an organization supposes good collaboration between marketing, design and communication abilities. In absence of these convergences, the image is inconsistent and does not transmit to the people the desired message.

Communication represents a fundamental feature of a human being and expresses the universal, apart from interconnection which refers to instruments, to techniques and technologies which facilitate and amplify the communication process between individuals and collectivity, by conferring a mass character, in certain cases.

The components of the communication strategy of a company are: image and identity of the corporation, publicity by the company and means of spreading publicity, relations with mass media, marketing communications, financial communications, communication with the employees, relations with the community, charitable actions of the corporation, relations with the authorities, communication in crisis situations, continuity, profitability, social politics.

\section{References}

[1] C. Bovee, J. Thill and B. Schatzman, "Business communication today" (7th ed.), Prentice Hall, Upper Saddle River, New Jersey, 2002, pp. 746.

[2] R. Buck, "The communication of emotion", Guilford Press, New York, 1984, pp. 387

[3] J. DeVito, "The Interpersonal Communication Book", (12th ed.), Pearson/Allyn and Bacon, Boston, Massachusetts, 2009, pp. 421

[4] R. Emanuel, "The case for Fundamentals of Oral Communication.Community", College Journal of Research and Practice, 29 (2), 2005, pp. 159-164.

[5] J, Grunig (editor); D. Dozier, W. Ehling, L. Grunig, F. Repper and J. White, "Excellence in public relations and communication management", Routledge, New York, 2008, pp. 701

[6] M.E. Guffey, "Business Communication: Process and Product" (6th ed.), South-Western Cengage Learning, Mason, Ohio, 2008, pp. 690

[7] M.E. Guffey and D. Loewy, "Essentials of Business Communication" (9th ed.), South-Western Cengage Learning, Mason, Ohio, 2012, pp. 587

[8] M.L. Knapp and A.L. Vangelis, "Interpersonal Communication and Human Relationships" (6th Edition), Allyn and Bacon, Boston, Massachusetts, 1996, pp. 468

[9] Ph. Kotler, "Marketing Management", Teora Publishing, Bucharest, 1997

[10] M. Kunczik and A. Zipfel, "Introduction into science of journalism and communication", Publishing Comp, 1998, pp. 16

[11] L.K. Lewis, "Communicating change: Four cases of quality programs". Journal of Business Communication, 37, 2000, pp.150-153

[12] S.W. Littlejohn and K.A. Foss, "Theories of Human Communication", (9th ed.), Thomson Higher Education, Belmont, California, 2008, pp. 391

[13] K. Locker and D. Kienzler, "Business and administrative communication" (9th ed.), McGraw-Hill/Irwin, New York, 2009, pp. 749

[14] P.E. Madlock, "The link between leadership style, communicator competence, and employee satisfaction". Journal of Business Communication, 45, 2008, pp. 77-78.

[15] J. Maes, T. Weldy and M. Icenogle, "A managerial perspective: Oral communication competency is most important for business students in the workplace", The Journal of Business Communication, 31(1), 1997, pp. 78-82

[16] K. Miller, "Communication Theories: Perspectives, Processes and Contexts", McGraw Hill, New York, 2005, pp. 345

[17] S.P. Morreale, L.W. Hugenberg and D.W. Worley, "The Basic Communication", Course at U.S. Colleges and Universities in the 21 stCentury: Study VII. Communication Education, 55 (4), 2006, pp.430-433. 
[18] A. Neamtu and L. Neamtu, "Communication and public relations”, Academica Brancusi, Targu-Jiu, Romania, 2009

[19] P. Pelsmacker and P.C. Neijens, "New advertising for-mats: How persuasion knowledge affects consumer responses". Journal of Marketing Communications, 2012, 18, pp.1-4.

[20] Şt. Prutianu, "Communication manual', Publishing Comp. Polirom, Iaşi, 2000, pp. 21.

[21] V.P. Richmond, D.R. Lane and J.C. McCroskey, "Teacher immediacy and the teacher student relationship, 2006, (pp. 187-191). Boston: Pearson Education.

[22] T. Rotaru and P. Ilut, "Sociology", Publishing Comp. Mesagerul Cluj Napoca, 1995, pp. 67

[23] W. Severin and J. Tankard, "Communication theories", Addison Wesley Longman, New York, 2010, pp. 409

[24] D. Silverman, "Relations in the field". In Doing qualitative P.R. Smith, "Marketing Communication", Kogan Page Limited, London, 1993, pp. 337

[25] S. Tubbs and S. Moss, "Human communication: principles and contexts" (11th ed.), McGraw-Hill Higher Education, New York, 2002, pp. 510

[26] M. Voicu and C Rusu, "ABC of management communication", Publishing Comp. "Danubius", 1998, pp. 16.
[27] P. Watzlawick, J.B. Bavelas, D.D. Jackson and B. O'Hanlon, "Pragmatics of human communication: A study of interactional patterns, pathologies, and paradoxes", Faber\&Faber, London, 1967

[28] J. White and L. Mazur, "Strategic communications management. Making public relations work", Addison Wesley Publishing Company, 1995, pp. 28

[29] P. Pelsmacker and P.C. Neijens ,New advertising for-mats: How persuasion knowledge affects consumer responses. Journal of Marketing Communications. 2012, 18:1-4.

[30] A. Neamtu and L. Neamtu, Strategic alternative related to market demand, Analele UCB, series Economy, ISSN 18447007, 6, 2014

[31] H. Wang, J.R. Wuebker, S. Han and D.M. Ensley, Strategic alliances by venture.Capital backed firms: an empirical examination. Small Business Economics. 2012, 38(2):186-94.

[32] U. Ozmel, D Robinson and T. Stuart, Strategic alliances, venture capital, and exit decisions in early stage high-tech firms. Journal of Financial Economics, 2013, 107(3):663-667.

[33] R. Gulati, F. Wohlgezogen and P. Zhelyazkov, The Two Facets of Collaboration: Cooperation and Coordination in Strategic Alliances, The Academy of Management Annals. 2012, 6(1):560-76. 